\title{
Fluxos Desiguais do Sistema Financeiro e Inovativo: uma Análise das Assimetrias entre Países Ricos e Pobres
}

\section{Unequal Flow of the Financial System and Innovative: an Analysis of Inequality Between Rich and Poor Countries}

\author{
Frederick Fagundes Alves* \\ Silvia Harumi Toyoshima** \\ Daniela Almeida Raposo Torres***
}

\begin{abstract}
Resumo: Este artigo objetiva identificar a relação entre o sistema financeiro e o sistema de inovação e preencher uma lacuna que há na literatura sobre financiamento do progresso tecnológico. A partir de uma análise empírica em painel para dois grupos de países (de maiores e menores PIB per capita), no período entre 1980 e 2010, verifica-se a existência de uma relação de causalidade entre a variável financeira e a variável tecnológica para o caso dos países desenvolvidos. Já para os países menos desenvolvidos observa-se a ausência de causalidade de longo prazo entre o sistema financeiro e o tecnológico. Conclui-se que há necessidade de adoção de políticas de estímulo ao desenvolvimento tanto do sistema financeiro doméstico quanto do sistema nacional de inovação nas economias mais pobres, visando elevar sua taxa de crescimento de maneira sustentada.
\end{abstract}

Palavras-chave: Sistema nacional de inovação. Sistema financeiro. Causalidade.

Abstract: This paper aimed to identify the relationship between the financial system and the innovation system, and fill a gap in the literature that there is financing of technological progress. From empirical analysis panel for two groups of countries (highest and lowest GDP per capita), in the period between 1980 and 2010, there was the existence of a relationship of causality between the financial variable and technological variable, in case of developed countries. Already, for peripheral countries, there is a lack of long-term causality between the financial system and the technological. It is concluded that there is need to adopt policies to encourage the development of both the domestic financial system as the national system of innovation in poorer economies, aiming to raise its growth rate on a sustained basis.

Keywords: National innovation system. Financial system. Causality.

JEL Classification: O16; O31; O57.

* Mestrando em Economia pela Universidade Federal de Viçosa (UFV). E-mail: frederick.alves@ ufv.br

* $\quad$ Doutora em Ciência Econômica pela Universidade Estadual de Campinas. Professora associada do Departamento de Ciências Econômicas da Universidade Federal de Viçosa (UFV). E-mail: htsilvia@ufv.br

*** Doutora em Economia pela Universidade Federal de Minas Gerais. Professora do Departamento de Economia da Universidade Federal de São João del Rei (UFSJ).

E-mail: daniraposo@ufsj.edu.br 


\section{1 lntrodução}

O propósito deste artigo é fazer uma ponte teórica capaz de unir o sistema nacional de inovação (SNI) e o sistema financeiro (SF), através das abordagens neoschumpeteriana e pós-keynesiana. Pretende-se a partir disso discutir os obstáculos enfrentados pelo SF para desenvolver-se e verificar se este afeta o sistema de inovação (SI). Para isso, procurou-se estabelecer as relações causais entre o grau de desenvolvimento dos SI e os sistemas financeiros das economias.

Existe uma extensa literatura que aborda a importância do progresso tecnológico para o crescimento e desenvolvimento econômico. Ademais, de acordo com a corrente de pensamento evolucionária, ${ }^{1}$ o progresso tecnológico depende do SNI de um país e/ou região. Logo, o SI é um determinante importante do desenvolvimento econômico (FREEMAN, 1995; NELSON, 1993; LUNDVALL, 1992).

Schumpeter (1982), em sua teoria do desenvolvimento econômico, já discutia sobre a importância do crédito para o processo de inovação. Para os empreendedores tornarem-se forças motrizes em um processo de inovação, deveriam convencer os bancos a fornecerem crédito com o objetivo de financiar a inovação. A implementação de algo novo dependeria, assim, de dinheiro novo, o qual deveria ser gerado pela expansão do crédito, via SF. Consequentemente, a presença de um SF evoluído seria crucial para facilitar o processo de inovação, considerado pelo autor como força propulsora do crescimento econômico.

Ademais, o investimento em novos produtos e processos, ou seja, o investimento em inovação, tem um elemento de incerteza real, como também de incerteza relacionado aos negócios. A incerteza real refere-se à impossibilidade de realizar cálculos acurados da taxa de retorno desse tipo de projeto de investimento, conceito compatível com a visão pós-keynesiana, segundo a qual o mundo econômico não é ergódico (CARVALHO, 1992; AMADO, 2000). Longe de reduzir essas incertezas, as inovações tecnológicas tendem a aumentá-las. No entanto, uma vez que a inovação seja estabelecida num ambiente empresarial mais confiante, apoiada por uma infraestrutura e arranjos institucionais integrados, a incerteza é amenizada e o SF desempenha seu papel de financiador das atividades inovativas.

Fica evidente, portanto, a relação direta entre SI eficientes e financiamento. Em outras palavras, maior disponibilidade de recursos financeiros para o exercício das atividades inovativas será encontrada em sistemas nacionais plenamente constituídos.

Entretanto, pouca atenção tem sido dada às formas como os principais agentes do SI terão acesso aos financiamentos necessários para a realização de investimentos de longo prazo. Os diversos trabalhos sobre o assunto têm focalizado ins-

1 Ver em Nelson e Winter (1982) o desenvolvimento tanto dos antecedentes quanto das premissas básicas da abordagem evolucionária. 
tituições, redes e processos interativos de aprendizado, como o de Godin (2009), que desenvolveu a tese de que outras instituições de pesquisas, como indústrias, governos e instituições privadas, estão se unindo às universidades. Essas instituições são, no entanto, dependentes de fontes de financiamento.

Ainda, autores como Corder (2008) e Rezende e Vedovello (2006) abordam os incentivos à inovação no Brasil, enquanto que Romero, Silveira e Britto (2011) tratam da causalidade entre o SNI e a balança de pagamentos. Romero e Jayme Jr. (2009) analisam os impactos da preferência pela liquidez e o desenvolvimento regional de inovação do Brasil.

Outros autores analisam o SNI, porém dão pouca ênfase às formas que este será financiado, como em Quintero Campos (2011), que elucida as políticas de ciência e tecnologia em diferentes zonas regionais para países menos desenvolvidos, e Lundvall et al. (2009), que tratam da inserção dos SI nos países em desenvolvimento.

Assim, é necessário preencher a lacuna representada pelo escasso debate entre SI e financiamento, principalmente após o racionamento de crédito causado pela crise financeira. A dimensão financeira do processo inovativo pode assumir proporção ainda maior nos países menos desenvolvidos, uma vez que o financiamento para o investimento é escasso, incluindo aquele para inovação. De fato, grande parte desses países não possui estruturas financeiras funcionais, isto é, os bancos privados geralmente não financiam investimentos de longo prazo.

Como forma de contribuição, este artigo reportará as dificuldades enfrentadas pelos agentes financiadores, visto que há escassez de discussão entre os economistas da inovação sobre os impactos enfrentados recentemente. ${ }^{2}$ Além disso, tentar-se-á fazer uma ponte teórica entre as abordagens neoschumpeteriana e pós-keynesiana, ligando os SNIs ao SF.

A hipótese básica deste estudo é de que a estrutura atual do SF dos países menos desenvolvidos representa um entrave importante para o amadurecimento dos seus SI. Espera-se, também, que o grau de desenvolvimento do SF doméstico cause, no sentido de Granger, o progresso tecnológico de um país (ou grau de desenvolvimento relativo do seu SI).

O restante do artigo está dividido da seguinte forma além desta introdução: a segunda seção explicita uma abordagem evolucionária sobre inovação, seguida por uma apresentação das características existentes num SNI; a terceira seção aborda a ótica pós-keynesiana, utilizada como uma tentativa de ligar o SF ao SNI; a quarta seção apresenta os métodos utilizados para realização dos testes empíricos, bem como o detalhamento dos testes utilizados, a partir da relação entre SF e SI, constatada na parte teórica; a quinta seção mostra os resultados obtidos a

2 Para exceção de discussão, ver Perez (2010) e Filippetti e Archibugi (2010). 
partir dos testes realizados; na sexta seção, para finalizar, algumas considerações são colocadas, a título de conclusão do artigo.

\section{Sistema Nacional de Inovação sob a Ótica Neoschumpeteriana}

Pode-se definir inovações como a produção de novo conhecimento ou novas combinações de conhecimento existentes transformados em produtos ou processos economicamente significantes. O ambiente, os atores, as instituições envolvidas, nesse processo de produção do novo conhecimento, elucidam o conceito de um SI.

As ideias básicas sobre inovação provêm da obra Système national d'économie politique, de 1841, elaborado por Friedrich List, que tentou explicar o processo de catching up da Alemanha sobre a Inglaterra e o caso dos países em desenvolvimento. Segundo Gordon (2009), List antecipou ideias contemporâneas sobre o SNI, incluindo a importância da acumulação tecnológica. Mais tarde, Joseph Schumpeter ${ }^{3}$ foi o teórico que se tornou referência para a formulação do conceito de SNI, destacando a grande importância da inovação como motor do capitalismo.

Porém, de acordo com Gordon (2009), Christopher Freeman 4 pode ser considerado o pai da teoria atual sobre inovação, uma vez que amplia o conceito de SNI, antes restrito em um tripé de instituições (governo/universidade/empresa), tendo a ciência como principal meio de inovação. Freeman (1987), ao analisar o sistema nacional japonês, enfatiza as políticas sociais radicais de longo prazo adotadas por esse país, das quais se têm: pesquisa e desenvolvimento; melhorias na educação e laboratórios para desenvolver habilidades e capacitações; forte produção e importação de novas tecnologias; formação de engenheiros; e a proximidade entre o governo e o setor privado. Segundo Albuquerque (2004), esse estudo mais amplo de SNI abrange firmas e suas redes de cooperação e interação, universidades e institutos de pesquisas, instituições de ensino, sistemas financeiros, sistemas legais, mecanismos mercantis e não mercantis de seleção, governos e mecanismos e instituições de coordenação. ${ }^{5}$

Todo esse sistema interage e cria processos de "ciclos virtuosos". Por isso, é necessário apoiar-se na teoria para entender o papel de cada instituição no aprimoramento de um conceito mais amplo de SNI. Anteriormente, o desenvolvimento era restringido a um modelo simplista, com um fluxo circular estático e em equilíbrio entre universidades e empresas, sendo o governo apenas um ator regu-

\footnotetext{
3 Ver Schumpeter (1984).

4 Ver Freeman (1987).

5 Para mais detalhes, ver Albuquerque (2004).
} 
larizador dessa cadeia movida pela ciência, perdendo espaço para mercados em que a inovação é o principal meio para dinamização e diferenciação do mercado.

A teoria neoschumpeteriana entende inovação como sendo resultado da interação entre várias instituições. Esse conceito não se restringe somente à tecnologia, podendo ser também o avanço técnico em processos, produtos, organizacional, marketing, etc.. Ademais, não se restringe apenas ao lócus empresarial, podendo ser o sistema do mercado local, nacional ou internacional.

O conceito de SNI ampliado enfatiza as relações e cooperações entre os agentes, sendo de suma importância as trocas de informações entre pessoas e organizações para a construção de um ambiente inovativo. Porém, na maioria das vezes, esse conhecimento adquirido não é difundido facilmente, sendo utilizado como estratégia e domínio dentro do sistema capitalista.

Segundo Romero e Jayme Jr. (2010, 2009), o processo de desenvolvimento deve ser analisado, de forma individual e única, para cada nação, pois depende de sua composição histórica, social, cultural, educacional, etc. Portanto, a implantação de novas políticas para a criação de um SI deve ser adaptada, respeitando as especificidades de cada país e a heterogeneidade da estrutura produtiva e inovativa de cada região. Nesse contexto, o conceito de SNI constitui-se de um conjunto de características e relações socioeconômicas que um país/região deve possuir para empreender atividades de inovação e/ou imitação tecnológica.

\subsection{Peculiaridades dos Sistemas Nacionais de Inovação}

De acordo com Freeman (1995), Nelson (1993) e Lundvall (1992), um SI abrangente engloba tanto o processo de imitação tecnológica, e posteriormente sua difusão, quanto o processo de "empréstimo tecnológico", capacitação de inovação dessa tecnologia e, logo em seguida, a difusão desse conhecimento. Não existe um único SNI, já que este dependente da evolução histórica e social de cada país ou região.

A partir disso, algumas características podem ser observadas em países cujo SNI é considerado eficiente. A primeira característica consiste num sistema educacional de qualidade e com amplo acesso à população, a fim de que haja profissionais capacitados para o avanço científico e a realização de inovações incrementais.

Uma segunda característica é a existência de trade-off entre especialização e adaptação. Países com elevados níveis de especialização dificilmente se adaptarão às tecnologias de longo prazo, pois sempre estarão inovando em relação à tecnologia já existente.

Outra característica que também deve estar presente é a capacidade do sistema de financiamento investir nas firmas para que estas possam inovar e difundir 
tecnologia. Essas firmas necessitam de uma escala mínima de capital para aplicarem em pesquisas e novos processos.

A inovação como estratégia de desenvolvimento de um país deve ser priorizada por instituições de fomento à pesquisa, bancos em geral, empresas públicas e privadas, agentes de financiamento a projetos de investimento associados à formação e capacitação de ambientes inovadores, etc. Isso permitirá que o país atinja posição competitiva entre as empresas e amadureça o $\mathrm{SF}$, o qual dará suporte às novas pesquisas.

Todavia, o SF deve ser analisado, de forma cuidadosa, em razão da sua capacidade de viabilizar, ou inviabilizar, o desenvolvimento de um SI. De acordo com Amado (2000, 1997) e Romero e Jayme Jr. (2010), fatores como a não neutralidade da moeda, a preferência pela liquidez, o nível de organização desses agentes financeiros e o amadurecimento, tanto desse SF, quanto do SI, podem motivar maiores ou menores investimentos e crescimento, sendo levadas em consideração as particularidades de cada país. Para tanto, a seção seguinte introduz o mercado financeiro/monetário sob a ótica pós-keynesiana e une esse SF ao SNI.

\section{Ponte Teórica entre as Abordagens Evolucionária e Pós-Keynesiana}

A análise tanto dos créditos quanto dos depósitos é fundamental para entender o comportamento de cada país dentro do SF. O crédito concedido pelos bancos pode ser o ponto de partida para uma movimentação financeira mais dinâmica, pois cria depósitos e investimentos, permitindo a criação de novos créditos. Porém, há de se notar que as trajetórias dessas concessões de crédito não se limitam a um círculo de funcionamento perfeito, ocorrendo vazamentos financeiros entre regiões centrais (mais desenvolvidas) e regiões periféricas (menos desenvolvidas).

Segundo Romero e Jayme Jr. (2010) e Amado (1997), a preferência pela liquidez em regiões periféricas é maior devido ao alto risco de inadimplência da periferia, às mudanças da eficiência marginal do investimento (que é afetada por taxas de juros mais altas e menos oferta de crédito) e a maior incerteza da renda entre o público. Por outro lado, pela menor incerteza e menor volatilidade, a região central teria menor preferência pela liquidez e, por essa razão, apresenta uma economia mais dinâmica, com ativos mais líquidos, dificultando a concessão de crédito na periferia, reduzindo o investimento nesta região em favor do centro.

Em uma região subdesenvolvida, a escassez de crédito reforça o atraso, já que tanto a oferta quanto a demanda por crédito são baixos devido à falta de desenvolvimento, criando um círculo vicioso de causalidade cumulativa. Os bancos emprestam menos para regiões periféricas, dada a sua estrutura econômica e o baixo controle sobre suas atividades. Os bancos locais ou regionais, específicos em países periféricos, preferirão manter os níveis mais elevados de reservas e restringir 
empréstimos, incentivando a concentração bancária no centro. Assim, o processo de concentração bancária é reforçado.

De acordo com Friedman (1972 apud AMADO, 1997, p. 420), a relação de inovação entre centro e periferia se dá da seguinte forma: o centro, por ser mais dinâmico e mais desenvolvido, se torna responsável pela inovação, enquanto que a periferia tenta se adaptar e absorver as mudanças ocorridas, nos países centrais, com certo atraso de tempo. Esse ciclo acaba dando vantagens ao centro, em detrimento da periferia. Essas inovações podem ser adaptadas para o SF, pois a maioria ocorre em regiões mais desenvolvidas, dando vantagens aos bancos ali localizados, que possuem maior dinâmica e menor preferência por liquidez.

Tendo em mente o referencial pós-keynesiano, no qual a moeda não é neutra, no curto e no longo prazo, por representar elemento de fundamental importância no lado real da economia e não somente uma mercadoria facilitadora de trocas, tenta-se construir a relação entre SNI e SF. Discute-se a partir daí os obstáculos enfrentados pelo SF para desenvolver-se e se este afeta o SI. A teoria pós-keynesiana mostra que a moeda tem o poder de interferir no crescimento, levando em consideração o tempo e a incerteza de cada projeto de investimento. O tempo flui do passado para o futuro, e os atores agem de forma irreversível e sabem disso. A incerteza a qual se sujeitam esses atores decorre nesse tempo e não é quantificável.

Portanto, nesse ambiente de incerteza, amplia-se a preferência pela liquidez da moeda. Para tanto, num ambiente de crise em que os agentes demandam maior liquidez e, portanto, moeda, é necessário a elevação na taxa de juros para desestimular a retenção da liquidez. À medida que aumenta a taxa de juros, diminui-se a preferência pela liquidez ${ }^{6}$ (OREIRO, 1999).

6 Em um mundo de incerteza e propriedade privada, a moeda é uma forma segura de (ou que assegura a) riqueza. A retenção de moeda aplaca a incerteza dos agentes. Além disso, a moeda, devido aos pressupostos de sua elasticidade de produção e substituição nulas que tornam a moeda a base para contratos, é o limite máximo numa escala de liquidez. Essa escala de liquidez permite comparar os retornos de todos os ativos existentes na economia no mesmo espaço temporal. No modelo de escolha de ativos, proposto por Keynes e revisto em Carvalho (1992), os agentes podem demandar outros ativos de alta liquidez circulantes no mercado financeiro numa escala de preferência pela liquidez, em que no limite encontra-se a moeda. Nesse modelo, todo ativo apresenta sua taxa própria de juros (ou relativa aos outros ativos). A taxa própria de juros do ativo mede seus retornos esperados totais, dada a hipótese de incerteza e expectativas não ergódicas. Dado o estado das expectativas, os agentes escolhem ativos visando obter maiores retornos. Em geral, o aumento da demanda por esse ativo reduz sua taxa própria de juros ao longo do tempo. Contudo, o aumento da demanda pelo ativo moeda aumenta sua taxa própria de juros e seu retorno, ceteris paribus. A moeda apresenta rendimentos esperados nulos, negligenciáveis custos de retenção, valorização nula em termos monetários e o mais elevado prêmio de liquidez. Logo, a taxa própria de juros da moeda não reduz pari passu com as outras taxas de juros. Nesse caso, os agentes sempre demandam moeda em detrimento dos outros ativos, garantido a ela papel ativo na determinação da trajetória de crescimento da economia. Ver mais detalhes sobre os limites monetários ao crescimento em Amado (2000). 
Segundo Freitas (2009), os bancos criam moeda de maneira a conceder crédito sob a forma de reconhecimento de dívida contra si próprio e libertam os indivíduos de ficarem presos à acumulação de recursos, incentivando-os, assim, a aumentar os níveis de investimentos. Dessa forma, eles agem de acordo com o desempenho da economia e suas perspectivas de rentabilidade e risco, e exigem dos tomadores uma margem garantida dos empréstimos. Como todos os demais agentes econômicos, os bancos possuem preferência pela liquidez e expectativas em relação ao futuro, as quais orientam suas estratégias na busca por lucro.

Como o desejo dos bancos em se manter líquido depende de suas considerações pessimistas ou otimistas sobre o estado dos negócios ao longo do ciclo econômico, Freitas (2009) elucida que a evolução do crédito tende a ser pró-cíclica, principalmente se o sistema bancário for constituído por instituições privadas com fins lucrativos. Porém, essas expectativas podem levar ao aumento do risco e ao racionamento de crédito, desacelerando o crescimento econômico.

De acordo com Silber (2010), os efeitos da recente crise de 2008 foram mais drásticos para os países europeus porque os bancos estavam tão alavancados que os governos não tiveram condições fiscais de resgatá-los, e a ajuda dada a eles comprometeu o estímulo fiscal necessário para a recuperação da economia europeia. Nos Estados Unidos, por este ser o emissor da moeda de curso internacional e ter amplo limite de endividamento, a capacidade de resgatar instituições financeiras é muito maior. A partir das condições da crise a trajetória do dólar americano no mercado mundial estava determinada, se desvalorizando em termos reais em relação às principais moedas do mundo.

A teoria cepalina visualiza a vulnerabilidade macroeconômica dos países em desenvolvimento, incluindo a origem das moedas em que são expressas as dívidas externas desses países e as paridades que as acompanham, além das estruturas dos mercados financeiros e as pressões especulativas que esses mercados enfrentam. Assim, essas diferenças macroeconômicas estão ligadas ao fato de que as moedas transacionadas internacionalmente são as dos países desenvolvidos (centrais), levando ao entendimento de que as economias menos desenvolvidas são de alto risco e de fortes ciclos financeiros, dando maior abertura para fugas de investimento em ativos de "qualidade", supostamente localizados nos países centrais (COMISSÃO ECONÔMICA PARA A AMÉRICA LATINA E O CARIBE, 2002).

Entretanto, um aspecto relevante da economia mundial após a crise financeira é o papel do dólar como principal moeda de reserva no sistema monetário internacional. Os efeitos da crise financeira indicaram os elevados custos em se basear o sistema de pagamentos internacionais em uma única moeda. Segundo Silber (2010), os detentores de ativos denominados em dólar tiveram perdas patrimoniais importantes, e o crescimento desordenado da dívida externa e do governo americano coloca dúvidas cada vez maiores na qualidade dos ativos financei- 
ros americanos. A demanda por reservas externas deverá caminhar em direção a um sistema híbrido, em que algumas moedas terão um papel compartilhado com o dólar para oferecer liquidez ao sistema monetário internacional.

De acordo com Freitas (2009), a crise financeira desencadeou, de um lado, o aumento da aversão ao risco e à preferência pela liquidez nos países mais ricos ocasionando um movimento de fuga dos investidores globais e a interrupção das linhas de crédito comercial, resultando na desvalorização das moedas de várias economias, e, de outro lado, a retração da atividade econômica dos países centrais associada à desaceleração do SF e de queda no preço dos ativos, resultando em menor dinamismo do comércio internacional. Portanto, uma primeira característica da economia mundial que se esboça após a crise é que o SF será mais retraído, com maiores regulamentações, e que talvez reduza seus lucros e bônus.

Referente a Filippetti e Archibugi (2010), a grande maioria da empresas europeias, com exceção de países como Suíça, Suécia, Áustria e Finlândia, reduziram os investimentos em inovação, visto os efeitos da crise econômica.

Sendo assim, o investimento, variável dinâmica da economia em Keynes, depende das expectativas dos capitalistas quanto aos seus ganhos futuros. Num mundo de incerteza, a escolha dos empresários de investir em ativos ilíquidos associa-se ao elevado grau de confiança no futuro. $\mathrm{O}$ ritmo dos investimentos em ativos de capital depende do estado das expectativas, as quais são formadas com base em percepções subjetivas, revelando o caráter incerto das decisões de investir.

Como mencionado anteriormente, quando se considera inovações tecnológicas, a incerteza tende a aumentar. No entanto, uma vez que a inovação seja estabelecida, num ambiente empresarial mais confiante, apoiada por infraestrutura e arranjos institucionais integrados, a incerteza é amenizada e o SF desempenha, a contento, seu papel de financiador das atividades inovativas. Logo, se o SF nacional tiver familiaridade com a indústria e conhecimento das empresas, pode exercer importante função de apoio às inovações e/ou difusões tecnológicas.

\section{Metodologia}

Diante dos objetivos da pesquisa, apresenta-se nesta seção o instrumental analítico do artigo bem como a forma de tratamento dos dados. Visando testar a hipótese de que o SF produz ganhos de competitividade e estimula o progresso tecnológico em economias maduras, são realizados testes de raiz unitária, cointegração e de causalidade de Granger para os grupos de países amostrados. Para isso, os dados amostrados estão distribuídos em painel, compondo duas amostras: a primeira é composta pelo grupo de 10 países com os maiores 
PIB per capita, ${ }^{7}$ representando os países desenvolvidos, e a segunda, pelo grupo de 10 países com os menores PIB per capita, ${ }^{8}$ representando as economias mais pobres. Os dados estão dispostos para uma série composta por 31 anos, compreendendo o período de 1980 a 2010.

A partir do teste de estacionariedade, verifica-se se há relação de longo prazo entre o saldo em conta corrente e a participação do país na produção mundial per capita de patentes, através de testes de raiz unitária e do teste subsequente de cointegração para painéis. Do ponto de vista econômico, duas variáveis são cointegradas se tiverem entre elas uma relação de equilíbrio de longo prazo. Portanto, essa relação de longo prazo tem certamente implicações para o comportamento de curto prazo das variáveis, e deve haver algum mecanismo que influencia o comportamento das variáveis no curto prazo, de maneira a garantir a relação de equilíbrio de longo prazo.

O conceito econométrico de causalidade está ligado à predição temporal e não à questão de causa e efeito. Para isso, utiliza-se o teste de causalidade de Granger, que considera o sentido estatístico de causalidade para poder fazer uso de valores passados de determinada variável para previsões de outras. Esse teste utiliza como hipótese nula a ausência de causalidade entre as variáveis. Se identificada a não estacionariedade das variáveis, pode-se fazer o teste com as mesmas diferenciadas, caso seja ignorada quaisquer relações de cointegração entre elas.

\subsection{Fonte e Tratamento de Dados}

Do ponto de vista empírico, o estudo partiu da construção de indicadores de progresso tecnológico e de crédito, visando corroborar, por meio de evidências empíricas, as possíveis relações de causalidade.

Para quantificar a relevância dos bancos e das bolsas de valores, utilizaram-se dados fornecidos pelo Banco Mundial (WORLD BANK, 2012). As informações consistem em séries históricas anuais de:

a) crédito bancário (todo crédito doméstico concedido na economia oriundo do setor bancário, salvo para os bancos centrais); e

b) capitalização de mercado das empresas listadas nas bolsas de valores (o preço das ações multiplicado pelo número de ações, ou seja, o somatório dos preços de todas as companhias listadas na bolsa de valores) para o período entre 1980 e 2010.

\footnotetext{
$7 \quad$ Amostra de países com os maiores PIB per capita: Luxemburgo, Noruega, Suíça, Dinamarca, Austrália, Suécia, Estados Unidos, Holanda, Canadá e Irlanda. 
A variável crédito bancário, fornecida pelo Banco Mundial, refere-se ao percentual do PIB de cada país (domestic credit provided banking sector, \% of GDP). Neste trabalho, recalculou-se tal variável para ser definido seu valor real em dólar americano a partir do PIB per capita em valores correntes de cada país, disponíveis pelo Banco Mundial. A variável crédito doméstico (net domestic credit), fornecida em valores correntes de cada país, também foi transformada em dólares, através da série histórica de taxa de câmbio de cada país, também fornecida pelo Banco Mundial. Após serem adaptadas, essas variáveis de crédito bancário de cada país foram somadas:

$$
C R E_{i t}=C R E B_{i t}+C R E D_{i t}
$$

em que $\mathrm{CREB}_{\mathrm{it}}=$ crédito bancário como porcentagem do $\mathrm{PIB}, \mathrm{e} \mathrm{CRED}_{\mathrm{it}}=$ crédito doméstico como porcentagem do PIB. ${ }^{9}$

A variável capitalização de mercado foi mensurada em dólar corrente. Tanto a variável crédito bancário quanto a de capitalização de mercado foram recalculadas para definição do valor per capita em dólar americano corrente. Para quantificar a dimensão industrial-inovativa, utilizou-se a metodologia adotada por Herskovic, Ribeiro e Albuquerque (2008). Para representar o desenvolvimento científico, foi utilizada a média anual do número de artigos publicados em revistas internacionais por milhão de habitantes, fornecido pelo Institute of Scientific Information (ISI). Já para representar o progresso tecnológico, usou-se a média anual do número de patentes, concedido pelo United States Patent and Trade Office (USPTO), por milhão de habitantes (UNITED STATES PATENT AND TRADE OFFICE, 2012). Também foram utilizados os valores monetários de PIB per capita, também disponível na base de dados do Banco Mundial.

De acordo com Thirlwall (2005), parece haver nos países uma estreita associação entre o nível da renda per capita e o grau de industrialização, e também parece haver, nas várias nações, uma associação estreita entre o crescimento do PIB e o crescimento da indústria manufatureira. Os países que crescem com rapidez tendem a ser aqueles em que a participação da indústria no PIB aumenta com mais velocidade: os chamados países recém industrializados.

Com o intuito de confrontar os dados de artigos e patentes e de crédito bancário e capitalização de mercado foi criado um índice para medir o desenvolvimento científico-tecnológico e outro para medir o desenvolvimento financeiro. Porém, de acordo com Herskovic, Ribeiro e Albuquerque (2008),

9 O subscrito it indica, respectivamente, os diferentes países e anos a serem considerados. 
um índice sintético está sujeito a problemas, pois, ao transformar o progresso científico-tecnológico em um número e o desenvolvimento financeiro em outro, deixa-se de considerar vários aspectos qualitativos, à medida que cada país tem um desenvolvimento histórico distinto do SNI e do SF. No entanto, apesar das limitações, o cálculo é válido, pois permite analisar com maior clareza a relação incomum das duas dimensões.

Desse modo, calculando-se a média aritmética dos logaritmos naturais de artigos e patentes, tem-se o índice que representa o progresso científico-tecnológico (Var Tec), para o país i:

$$
\operatorname{Var} \operatorname{Tec}_{i}=\frac{\left(\operatorname{LnArt}_{\mathrm{i}}+\mathrm{LnPat}_{\mathrm{i}}\right)}{2}
$$

em que $\ln A r_{i t}$ é o logaritmo natural da média do número de artigos publicados por milhão de habitantes, e ln Pat $t_{i t}$ é o logaritmo natural da média do número de patentes concedidas pelo USPTO, por milhão de habitantes, entre 1980 e 2010 , para o país $i$.

Mantendo-se o mesmo método para encontrar a variável que representa o desenvolvimento financeiro no país $i$, também se utiliza a média aritmética dos logaritmos naturais de crédito bancário e capitalização de mercado:

$$
\operatorname{Var} \operatorname{Fin}_{i}=\frac{\left(\operatorname{Ln} \mathrm{CB}_{\mathrm{i}}+\operatorname{Ln} \mathrm{CM}_{\mathrm{i}}\right)}{2}
$$

na qual ln $C B_{i t}$ e ln $C M_{i t}$ são, respectivamente, o logaritmo natural do crédito bancário per capita do país i e o logaritmo natural da capitalização de mercado per capita do país i.

\section{Resultados e Discussão}

Para serem analisadas as disparidades existentes entre os dois grupos de países confrontados, deflacionou-se a série do produto por habitante durante o período de 2000 a 2010, transformando-se os valores nominais em valores reais. Com isso, percebem-se grandes diferenças nos valores do PIB per capita real em dólares. Enquanto Luxemburgo lidera o ranking com o maior PIB per capita, ultrapassando US $\$ 126$ mil por pessoa/ano, Malaui não chega a US\$ 425 habitante/ano (ver Tabela 1). Ao ser calculada a média do PIB por habitante durante a última década, um indivíduo residente em um país mais desenvolvido obtém, em média, US\$ 48.180 por ano, enquanto que num país pobre o indivíduo sobrevive com US $\$ 778 \mathrm{em}$ média, por ano. 


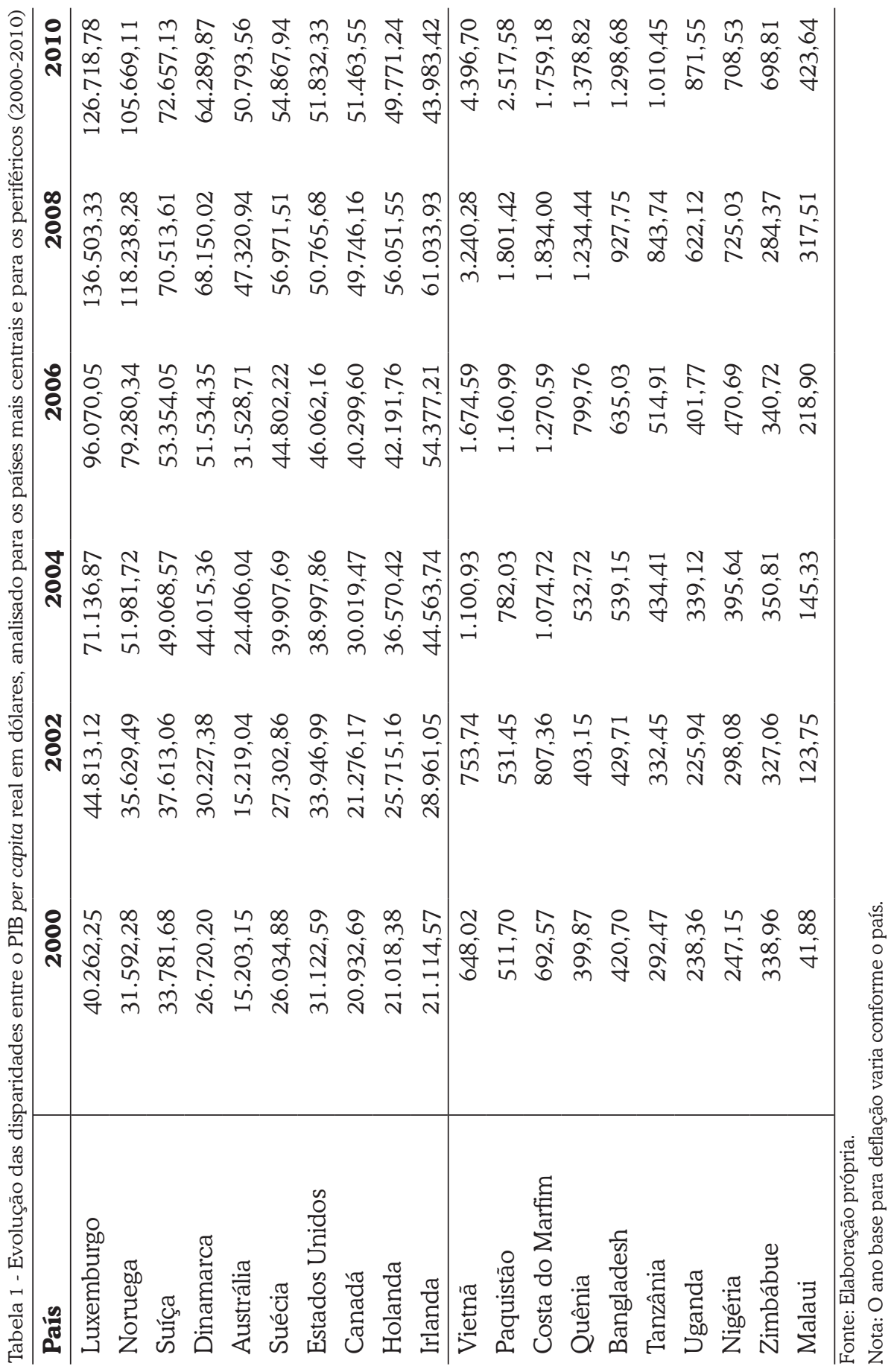


Para o ano de 2010, o produto por habitante de Luxemburgo chega a ser 299 vezes o valor obtido por Malaui. Dos 10 países que compõem a amostra dos países mais necessitados, sete são africanos (Malaui, Uganda, Tanzânia, Zimbábue, Quênia, Costa do Marfim e Nigéria) e três asiáticos (Bangladesh, Paquistão e Vietnã). Nigéria e Zimbábue são países em que o produto per capita é inferior a US $\$ 2,00$ ao dia, enquanto que o PIB per capita de Malaui ultrapassa pouco 1 dólar ao dia (US\$ 1,16 per capita/dia). Mesmo o PIB per capita do Vietnã (maior produto por habitante entre o grupo de países mais pobres) é dez vezes inferior ao PIB per capita irlandês (menor produto por habitante presente na amostra dos países mais ricos).

Após uma breve análise comparativa da distribuição de renda entre os dois grupos de países, passa-se então à interpretação dos modelos rodados, com o intuito de analisar o sistema monetário-financeiro e também o científico-tecnológico de ambos os grupos.

Para verificar se há relação de longo prazo entre Var Tec (SI) e Var Fin (SF), realizou-se testes de raiz unitária e cointegração para painéis. Para que a série temporal fosse testada a ponto de saber se há estacionariedade ou não em suas variáveis, usou-se o teste de raiz unitária, que apresenta como hipótese nula $\left(\mathbf{H}_{\mathbf{0}}\right)$ a existência de raiz unitária e como hipótese alternativa $\left(\mathbf{H}_{\mathbf{1}}\right)$ a não existência de raiz unitária na série temporal.

Tabela 2 - Testes de estacionariedade das séries Var Tec e Var Fin para os países desenvolvidos (1980-2010)

\begin{tabular}{c|c|c|c|c}
\hline \multirow{2}{*}{ Teste } & \multicolumn{2}{|c|}{ Série Var Fin } & \multicolumn{2}{c}{ Série Var Tec } \\
\cline { 2 - 5 } & Valor de t & P-valor & Valor de t & P-valor \\
\hline Levin, Lin \& Chu t & $-1,35$ & 0,08 & 1,21 & 0,89 \\
$\begin{array}{c}\text { Im, Pesaran and } \\
\text { Shin W-Stat }\end{array}$ & $-0,84$ & 0,20 & 0,57 & 0,71 \\
ADF - Fisher Chi- & 19,06 & 0,51 & 34,44 & 0,02 \\
$\begin{array}{c}\text { square } \\
\text { PP - Fisher Chi- } \\
\text { square }\end{array}$ & 21,58 & 0,36 & 89,80 & 0,00 \\
\hline
\end{tabular}

Fonte: Elaboração própria.

De acordo com os dados da Tabela 2, as séries Var Tec e Var Fin não são estacionárias quando testadas separadamente, havendo a presença de raiz unitária para os países mais ricos. A princípio, parece não haver uma relação de longo prazo entre as variáveis testadas, apesar de que, quando inserida a primeira diferença em ambas as séries, elas se mostraram estacionárias. 
Tabela 3 - Testes de estacionariedade das séries Var Tec e Var Fin para os países menos desenvolvidos (1980-2010)

\begin{tabular}{c|c|c|c|c}
\hline \multirow{2}{*}{ Teste } & \multicolumn{2}{|c|}{ Série Var Fin } & \multicolumn{2}{c}{ Série Var Tec } \\
\cline { 2 - 5 } & Valor de t & P-valor & Valor de t & P-valor \\
\hline $\begin{array}{c}\text { Levin, Lin E Chu t } \\
\text { Im, Pesaran and } \\
\text { Shin W-Stat }\end{array}$ & $-1,94$ & 0,02 & $-3,11$ & 0,00 \\
ADF - Fisher Chi- & 34,84 & 0,02 & $-4,45$ & 0,00 \\
$\begin{array}{c}\text { square } \\
\text { PP - Fisher Chi- } \\
\text { square }\end{array}$ & 108,11 & 0,00 & 125,47 & 0,00 \\
\hline
\end{tabular}

Fonte: Elaboração própria.

Referente aos resultados presentes na Tabela 3, a série tecnológica é estacionária, diferentemente da série financeira, que é identificada presença de raiz unitária, quando testado o caso dos países periféricos. Os resultados acima indicam presença de raiz unitária na série Var Fin, quando testada separadamente. Portanto, a hipótese nula de raiz unitária não é rejeitada para as variáveis individuais nessa série.

A partir dos resultados obtidos nas Tabelas 2 e 3, é necessário realizar o teste de cointegração com o intuito de analisar a ordem de integração das séries consideradas neste estudo. Para isso, de acordo com Gujarati (2006), é utilizado o teste d de Durbin-Watson obtido da regressão cointegrante.

Caso $d$ calculado for menor que 0,511 , rejeitamos a hipótese de cointegração no nível de $1 \%$. Nesse caso, o valor $d$ de 2,07 para os países desenvolvidos está acima do nível crítico, o que sugere que Var Tec e Var Fin são cointegradas. Para o caso dos países menos desenvolvidos, o valor $d$ foi de 1,93, indicando que nesse caso as variáveis financeira e tecnológica também se cointegram. Além disso, os testes de cointegração mostram que a hipótese nula de não cointegração não será aceita com $92 \%$ de confiança para a amostra dos países ricos e com $96 \%$ para o caso dos países periféricos.

Portanto, os resultados sugerem que Var Tec e Var Fin são cointegradas, tanto para o grupo de países com maiores PIB per capita quanto para o grupo com os menores PIB per capita. Embora individualmente as variáveis exibam um caminho aleatório, com presença de raiz unitária, conjuntamente parece haver uma relação de longo prazo entre essas variáveis, em que elas não se afastarão uma da outra.

Parte-se então para a análise de causalidade de longo prazo entre as variáveis testadas. Para identificar-se essa relação, é realizado o teste de causalidade Granger com 2 a 5 defasagens no tempo. Nesse caso, a variável nula $\left(\mathrm{H}_{0}\right)$ é de que não há 
relação de longo prazo entre as variáveis, enquanto que a variável alternativa $\left(\mathrm{H}_{1}\right)$ mostra o oposto.

Ao analisar a causalidade para os países desenvolvidos, observa-se que tanto a variável tecnológica quanto a variável financeira são dependentes uma da outra, ocorrendo um processo de causalidade, apesar da variável financeira não causar a variável tecnológica quando analisado com duas defasagens, como mostrado na Tabela 4.

Tabela 4 - Teste de causalidade de Granger de longo prazo entre Var Tec e Var Fin para os países desenvolvidos

\begin{tabular}{c|c|c|c|c}
\hline Defasagens lags & \multicolumn{2}{|c|}{ Var Tec não causa Var Fin } & \multicolumn{2}{c}{ Var Fin não causa Var Tec } \\
\hline \multirow{2}{*}{2} & Valor de F & p-valor & Valor de F & p-valor \\
3 & 5,03 & 0,00 & 0,11 & 0,89 \\
4 & 3,20 & 0,02 & 2,90 & 0,03 \\
5 & 3,78 & 0,00 & 3,53 & 0,00 \\
& 3,15 & 0,00 & 2,97 & 0,01 \\
\hline
\end{tabular}

Fonte: Elaboração própria.

Portanto, ao se tratar de países com sistemas financeiros e tecnológicos desenvolvidos e com instituições maduras e bem estruturadas, têm-se casos de sucesso em que o SF dá suporte ao desenvolvimento do SI e vice-versa.

Já ao analisar os resultados do modelo de causalidade para os países menos desenvolvidos, disposto na Tabela 5, observa-se que não há um processo de causalidade. Nesse caso, nem a variável tecnológica causa a variável financeira, nem a Var Fin causa Var Tec, para nenhuma das defasagens testadas. 
Tabela 5 - Teste de causalidade de Granger de longo prazo entre Var Tec e Var Fin para os países menos desenvolvidos

\begin{tabular}{c|c|c|c|c}
\hline Defasagens lags & \multicolumn{2}{|c|}{ Var Tec não causa Var Fin } & \multicolumn{2}{c}{ Var Fin não causa Var Tec } \\
\hline & Valor de F & p-valor & Valor de F & p-valor \\
\hline 2 & 1,60 & 0,20 & 0,73 & 0,48 \\
3 & 1,44 & 0,23 & 0,69 & 0,55 \\
4 & 1,00 & 0,40 & 0,52 & 072 \\
5 & 0,95 & 0,44 & 1,28 & 0,27 \\
\hline
\end{tabular}

Fonte: Elaboração própria.

A partir do estudo teórico, já era esperado que em países mais pobres não houvesse o mesmo avanço e progresso que os países mais dinâmicos. Tanto o SF quanto o SI são altamente dependentes dos países centrais, através de indústrias transnacionais, montadoras e bancos privados internacionais. Além disso, tanto as instituições financeiras quanto as instituições que promovem o progresso tecnológico na maioria das vezes se colocam acuadas, pois esses países são vistos como de alto risco de investimento, e por esse motivo atraem pouco capital.

Segundo Sachs (2005), para que o desenvolvimento econômico seja possível nos países de baixa renda, deve-se, a princípio, integrar de forma mais eficiente a ciência e a tecnologia com estratégias básicas de desenvolvimento nesses países. Em geral, a ciência tem sido considerada como assunto de países ricos, enquanto se espera que as nações pobres se concentrem em uma boa administração, em reformas de mercado, entre outros fatores. Além disso, os países mais pobres carecem de uma base científica mínima necessária para gerar inovação.

Ao tratar a indústria como vetor central da inovação, justifica-se mais uma vez os resultados alcançados neste trabalho, pois os países muito pobres praticamente não possuem grandes polos industriais e com relevância em inovação de produtos ou processos. Além do mais, esses países requerem muitos outros fatores e melhorias institucionais que estão além de apenas um SF desenvolvido. Ou seja, mesmo que o SF desses países possuísse maturidade suficiente, outros fatores particulares ao desenvolvimento e da história desses países os impede de alcançar um patamar inovativo comparado aos de países altamente ricos em propriedade intelectual.

Grande parte dos problemas também se deve às imperfeições e assimetrias dos mercados, à proteção aos direitos de propriedade intelectual e, também, às dificuldades financeiras para investimento em capital de risco. Os problemas e limitações não estão somente no mercado privado. A inexistência de capacidade científica e, portanto, inovativa, dos setores governamentais dos países mais pobres e a falta de poder aquisitivo desses governos constituem elementos fundamentais da 
estagnação e do isolamento tecnológico. Em muitos desses países os governos se encontram financeiramente enfraquecidos, de modo que têm dificuldades em investir em ciência e tecnologia e até mesmo de serem usuários finais das inovações criadas em outros países (SACHS, 2005).

Deve-se considerar também que a inovação tratada neste trabalho não se refere àquela gerada apenas na indústria. São considerados também os avanços em marketing, em processo e operacionais advindos de universidades e demais instituições de ensino e pesquisa. Nesse sentido, grande parte da inovação é reflexo da qualidade educacional oferecida à população, o que mais uma vez coloca os países mais pobres em desvantagem por não possuírem recursos suficientes para investimentos em educação.

Para que as desigualdades entre os países sejam reduzidas, de modo que todos alcancem padrão similar de desenvolvimento, Carvalho (2011) sugere que todos os países devem fornecer à população uma educação tecnológica que possibilite não apenas copiar conhecimentos existentes em outros países, mas também produzir seus próprios conhecimentos. A autora salienta ainda que a busca da autonomia tecnológica passa pela autonomia na produção do conhecimento. Seguindo o pensamento neoschumpeteriano, até mesmo para que haja cópia, o mínimo de investimento em conhecimento deve ser despendido. Faz-se, portanto, necessária a criação de programas de pesquisas que coloquem como prioridade a solução de problemas específicos do país, e não a criação de programas que somente preparem os técnicos para absorção de conhecimentos produzidos em outros países, que nem sempre têm relação com seus problemas.

Segundo Sachs (2005), os países mais pobres podem ser considerados como excluídos tecnologicamente por serem importadores líquidos de tecnologia e terem poucas patentes de invenção. Esses países não são nem ao menos adaptadores de tecnologia e, em alguns casos, nem adotam as tecnologias criadas como bens de consumo. O grau de penetração de bens tecnológicos de consumo (como celulares e computadores pessoais), a taxa de difusão dessas tecnologias e a extensão dos mesmos apresentam índices extremamente baixos nos países mais pobres.

Portanto, os resultados alcançados neste trabalho confirmam que tanto a inovação tecnológica quanto o SF se movem juntos no tempo, com equilíbrio de longo prazo, para o caso dos países ricos. A diferença entre essas variáveis é aceitável. Esses resultados sugerem que existe alguma dose de evidência quanto à existência de causalidade no sentido de Var Tec causar Var Fin e vice-versa. Porém, essa mesma interpretação não pode ser considerada para o grupo de países mais pobres, visto que, nestes, tanto o SF quanto o tecnológico são imaturos, pouco desenvolvidos ou até mesmo inexistentes.

Porém, ressalta-se que este é um estudo de longo prazo, e os resultados encontrados no artigo podem não condizer com os observados atualmente, visto que 
toda a economia mundial e principalmente os países desenvolvidos foram afetados pela crise americana do mercado subprime, iniciada em 2008, seguida pela crise europeia a partir de 2011. Tais crises trouxeram incerteza quanto aos rendimentos futuros, e com isso houve retração da concessão de crédito, que afetou principalmente os países ricos. Porém, tal análise, com respeito à possível redução de produção científico-tecnológica, se torna muito vulnerável, visto que pouco tempo se passou desde o início da crise, e muitos dos países ainda sofrem pelos efeitos da desaceleração econômica.

Os resultados encontrados só foram possíveis dado que os países desenvolvidos têm bases muito bem estruturadas em estoque de conhecimento, qualidade educacional e grande capacidade de especialização tecnológica, apesar da recessão sofrida pelo SF. Diferentemente, os países pobres, além de não possuírem SNI maduros, com fortes características, seus SF são concentrados nas poucas regiões mais dinâmicas, realizando o mínimo de investimento de longo prazo.

\section{Considerações Finais}

Neste trabalho encontram-se evidências da existência de causalidade entre SI e SF, quando se tem estes desenvolvidos e bem estruturados. A discussão teórica e as evidências empíricas desse ponto sugerem o $\mathrm{SF}$ como parte integrante do SNI. Ou seja, ter desenvolvimento científico e tecnológico implica ter um SF desenvolvido e vice-versa.

A distribuição igualitária entre os países não corrige as diferenças existentes entre as economias, podendo até piorá-las. Cada região possui suas peculiaridades e particularidades, tanto pelas diferenças da capacidade das instituições em assimilar e tornar as normas efetivas, quanto pelos distintos efeitos que essas instituições produzirão entre os países desenvolvidos e em desenvolvimento. As distribuições diferenciadas dos benefícios entre as economias são evidentes, principalmente porque as políticas e padrões que vigoram são de países avançados. Com isso, as melhorias da geração de incentivos para o desenvolvimento intelectual e tecnológico mundial recaem fundamentalmente sobre os países desenvolvidos, pois nestes se concentram a geração de tecnologia.

Essa situação também está presente no campo financeiro. O estabelecimento de normas mais rígidas e a extensão dos padrões internos dos bancos à qualificação dos credores geram, na maioria das vezes, uma redução da oferta de crédito para os mercados classificados como de alto risco, o que afeta principalmente as pequenas economias e as empresas com pequeno capital e baixo poder de negociação.

Desse modo, o artigo contribui teórica e empiricamente para o debate sobre as diferenças das taxas de crescimento entre as economias mais e menos 
desenvolvidas. A redução dessas disparidades depende do desenvolvimento do SNI das economias mais pobres, o qual depende, entre outros fatores, do acesso ao financiamento de suas atividades. Com isso, um sistema econômico dinâmico aumentará os ganhos dos bancos e agências financiadoras, diminuindo o risco de perdas, as taxas e também a preferência pela liquidez, motivando a disponibilidade de crédito de longo prazo.

Portanto, a criação de políticas de concessão ao crédito de longo prazo, a presença de um SF evoluído e fortes estruturas dos SNI, tornam-se essenciais para facilitar o processo de inovação nos países em desenvolvimento e amenizar as disparidades existentes entre regiões mais ricas e mais pobres. Para isso, é sugerido que haja o controle das autoridades monetárias sobre a taxa de juros, ao ponto de que as agências financiadoras incorram em menor risco ao disponibilizarem crédito. Mantendo a estrutura financeira funcional, interligada e com baixo grau de incerteza, é esperado o aumento nos níveis de investimentos, o aumento da produção nacional, a redução nos níveis de desemprego e o aumento na concessão de créditos para mais investimentos.

\section{Referências}

ALBUQUERQUE, E. M. Apresentação. Revista Brasileira de Inovação, v. 3, n. 1, p. 9-34, jan.-jun. 2004.

AMADO, A. M. A questão regional e o sistema financeiro no Brasil: uma interpretação PósKeynesiana. Estudos Econômicos, São Paulo, v. 27, n. 3, p. 417-440, set./dez. 1997.

. Limites monetários ao crescimento: Keynes e a não neutralidade da moeda. Ensaios $\overline{\text { FEE, Porto Alegre, v. 21, n. 1, p. 44-81, } 2000 .}$

CARVALHO, F. J. C. Mr Keynes and the post Keynesians: principles of macroeconomics for a monetary production economy. Aldershot: Edward Elgar, 1992.

CARVALHO, M. G. Tecnologia, desenvolvimento social e educação tecnológica. Revista Educação 8 Tecnologia, n. 1, 2011.

COMISSÃO ECONÔMICA PARA A AMÉRICA LATINA E O CARIBE. Desigualdades e assimetria da ordem global. In: . Vigésimo nono período de sessões da Cepal: globalização e desenvolvimento. 2002. Cap. 3. Disponível em:

<http://www.eclac.org/publicaciones/xml/9/10029/Por-Cap3-Globalizacion.pdf > . Acesso em: 1 jun. 2012.

CORDER, S. Apolítica de financiamento à inovação no Brasil. Economia 8 Tecnologia, v. 4, n. 3, p. 87-100, 2008. Disponível em:

<http://ojs.c3sl.ufpr.br/ojs2/index.php/ret/article/view/27386/18236>. Acesso em: 1 set. 2012. 
FILIPPETTI, A.; ARCHIBUGI, D. Innovation in times of crisis: National Systems of Innovation, structure, and demand. Science Direct, v. 40, p. 179-192, 2010. Disponível em:

$<$ http://www.sciencedirect.com/science/article/pii/S0048733310001794>. Acesso em: 3 set. 2012.

FREEMAN, C. Changes in the national system of innovation. In: OECD Directorate for Science, Technology and Industry Ministerial Meeting. Paris: OECD, 1987.

FREEMAN, C. The "National System of Innovation" in historical perspective. Cambridge Journal of Economics, London, v. 19, n. 1, p. 5-24, Feb. 1995.

FREITAS, M. C. P. Os efeitos da crise global no Brasil: aversão ao risco e preferência pela liquidez no mercado de crédito. Estudo Avançados, v. 23, n. 66, p. 125-145, 2009. Disponível em: <http:/www.scielo.br/pdf/ea/v23n66/a11v2366.pdf>. Acesso em: 31 ago. 2012.

GODIN, B. National Innovation System (II): industrialists and origins of an idea. Montreal, Canada: Project on the Intellectual History of Innovation, 2009. (Working Paper, n. 4).

GORDON, J. L. P. L. Sistema Nacional de Inovação: uma alternativa de desenvolvimento para os países da América Latina. 2009. Disponível em:

$<$ http://www.sep.org.br/artigo/4_congresso/1782_672fb4a66da5fb1e3e07b4030528d067. pdf $>$. Acesso em: 3 nov. 2010.

GUJARATI, D. N. Econometria básica. 4. ed. Rio de Janeiro: Elsevier, 2006.

HERSKOVIC, B.; RIBEIRO, L. C.; ALBUQUERQUE, E. M. Efeitos recíprocos entre finanças e inovação. Belo Horizonte: UFMG/Cedeplar, 2008. (Texto para discussão, 332).

LUNDVALL, A-B. (Ed.). National systems of innovation: towards a theory of innovation and interactive learning. London: Pinter. 1992.

LUNDVALL, A-B. et al. (Ed.). Handbook of innovation systems and developing countries. Cheltenham, UK: Mixed Sources, 2009.

NELSON, R. (Ed.). National innovation systems: a comparative analysis. New York: Oxford University, 1993.

NELSON, R.; WINTER, S. An evolutionary theory of economic change. Cambridge: Harvard University, 1982.

OREIRO, J. L. O debate sobre os determinantes da taxa de juros. In: . Macroeconomia moderna: Keynes e a economia contemporânea. v. 2. Rio de Janeiro: Campus, 1999. cap. 10.

PEREZ, C. The financial crisis and the future of innovation: a view of technical change with the aid of history. Norway: The Other Canon Foundation; Tallin: Technological University of Tallinn, 2010. (Working Papers in Technology Governance and Economic Dynamics, n. 28).

QUINTERO CAMPOS, L. J. Aportes teóricos para el estudio de un sistema de innovación. Revista Innovar Journal, v. 20, n. 38, p. 57-76, sept.-dic. 2011. Disponível em: $<$ http://www.revistas.unal.edu.co/index.php/innovar/article/viewFile/22290/23201 > . Acesso em: 3 set. 2012. 
REZENDE, S. M.; VEDOVELLO, C. Agências de financiamento como instrumento de política pública em ciência, tecnologia e inovação: o caso da Financiadora de Estudos e Projetos (FINEP). Parcerias Estratégicas, v. 11, n. 23, p. 75-94, 2006. Disponível em:

$<$ http://seer.cgee.org.br/index.php/parcerias_estrategicas/article/viewFile/295/289>. Acesso em: 1 set. 2012.

ROMERO, J. P.; JAYME JR., F. G. Financial system, innovation and regional development: a study on the relationship between liquidity preference and innovation in Brazil. Belo Horizonte: UFMG/Cedeplar, 2010. (Texto para discussão, 412). Disponível em:

<http://www.cedeplar.ufmg.br/pesquisas/td/TD\%20412.pdf>. Acesso em: 31 ago. 2012.

ROMERO, J. P.; JAYME JR., F. G. Sistema financeiro, inovação e desenvolvimento regional: um estudo sobre a relação entre preferência pela liquidez e inovação no Brasil. Belo Horizonte: UFMG/Cedeplar, 2009. (Texto para discussão, 357). Disponível em:

<http:/www.cedeplar.ufmg.br/pesquisas/td/TD\%20357.pdf>. Acesso em: 2 set. 2012.

ROMERO, J. P.; SILVEIRA, F.; BRITTO, G. Structural change, national innovation system and balance-of-payments constraint: a theoretical and empirical analysis of the Brazilian case. Belo Horizonte: UFMG/Cedeplar, 2011. (Texto para discussão, 440). Disponível em:

<http://www.cedeplar.ufmg.br/pesquisas/td/TD\%20440.pdf>. Acesso em: 4 set. 2012.

SACHS, J. O divisor global de inovação. In: VARELLA, M. D. (Org.). Propriedade intelectual e desenvolvimento. São Paulo: Lex Editora, 2005.

SCHUMPETER, J. A. Capitalismo, socialismo e democracia. Rio de Janeiro: Zahar, 1984.

Economistas).

Teoria do desenvolvimento econômico. v. 1. São Paulo: Abril Cultural, 1982. (Os

SILBER, S. D. A economia mundial após a crise financeiro de 2007 e 2008. Revista USP, São Paulo, n. 85, p. 82-93, 2010. Disponível em:

<http://www.revistasusp.sibi.usp.br/pdf/revusp/n85/08.pdf>. Acesso em: 4 set. 2012.

THIRLWALL, A. P. A natureza do crescimento econômico: um referencial alternativo para compreender o desempenho das nações. Tradução Vera Ribeiro. Brasília, DF: Ipea, 2005.

UNITED STATES PATENT AND TRADEMARK OFFICE. United States Patent and Trademark Office (USPTO) database. 2012. Disponível em: < http://www.uspto.gov/main/patents.htm>. Acesso em: 12 maio 2012.

WORLD BANK. World Bank Indicadors Online. Washington, D. C: World Bank, 2010. Disponível em: <http://databank.worldbank.org/Data/Home.aspx> . Acesso em: 4 maio 2012.

Recebido em: 25/10/2012. Aceito em: 16/09/2013. 